\title{
Quantification of high-frequency sea-level fluctuations in shallow-water carbonates: an example from the Berriasian-Valanginian (French Jura)
}

\author{
Heiko Hillgärtner*, André Strasser \\ Institut de Géologie et Paléontologie, Université de Fribourg, Pérolles, CH-1700 Fribourg, Switzerland
}

Received 6 August 2001; accepted 21 March 2003

\begin{abstract}
When quantifying sedimentary processes on shallow carbonate platforms, it is important to know the highfrequency accommodation changes through time. Accommodation changes in cyclic successions are often analysed by simply converting cycle thickness to Fischer plots. This approach is not satisfactory, because it does not account for differential compaction, possible erosion, sea-level fall below the depositional surface, or subtidal cycles. An attempt is made here to reconstruct a realistic, high-frequency accommodation and sea-level curve based on a detailed facies and cyclostratigraphical analysis of Middle Berriasian to Lower Valanginian sections in the French Jura Mountains. The general depositional environment was a shallow-marine carbonate platform on a passive margin. Our approach includes the following steps: (1) facies interpretation; (2) cyclostratigraphical analysis and identification of Milankovitch parameters in a well-constrained chronostratigraphic framework; (3) differential decompaction according to facies; (4) estimation of depth ranges of erosion and vadose zone; (5) estimation of water-depth ranges at sequence boundaries and maximum flooding intervals; (6) estimation of mean subsidence rate; (7) classification of depositional sequences according to types of facies evolution: 'catch-up', 'catch-down', 'give-up', or 'keep-up'; (8) classification of depositional sequences according to long-term sea-level evolution: 'rising', 'stable', 'falling'; (9) calculation of 'eustatic' sea-level change for each depositional sequence using the parameters inferred from these scenarios, assuming that sea-level cycles were essentially symmetrical (which is probable in Early Cretaceous greenhouse conditions); (10) calculation of a sea-level curve for each studied section; (11) comparison of these curves among each other to filter out differential subsidence; (12) construction of a 'composite eustatic' sea-level curve for the entire studied platform; (13) spectral analysis of the calculated sea-level curves. Limitations of the method are those common to every stratigraphic analysis. However, the method has the potential to improve the original cyclostratigraphical interpretations and to better constrain the high-frequency sea-level changes that control carbonate production and sediment fluxes.
\end{abstract}

Keywords: carbonates; cyclostratigraphy; accommodation; sea-level changes; quantitative analysis

\footnotetext{
* Corresponding author. Present address: Shell International Exploration and Production BV, Technology Applications and Research, Volmerlaan 8, Postbus 60, 2280 AB Rijswijk, The Netherlands. Tel.: +31-70-4473101.

E-mail address: heiko.hillgartner@shell.com (H. Hillgärtner).
} 


\section{Introduction}

The analysis of high-frequency accommodation changes on shallow-water carbonate platforms is commonly performed by using Fischer plots or modified versions thereof that plot cumulative departure from mean cycle thickness against cycle number (e.g. Fischer, 1964; Read and Goldhammer, 1988; Goldhammer et al., 1990; Sadler et al., 1993; Martin-Chivelet et al., 2000). By this method, long-term sea-level and subsidence histories are interpreted, and a timing of the studied stratigraphical interval can be proposed if a pattern reflecting Milankovitch cyclicity is recognised. The use of Fischer plots is a simple and comparatively objective way to analyse stacking patterns of beds in peritidal successions, but a number of restrictions are inherent. It does not account for unfilled accommodation space where sediment accumulation does not reach the water surface during a sea-level cycle. Equally, erosion when sea level falls below the depositional surface is neglected. Furthermore, because of facies-dependent differential decompaction, accommodation changes directly calculated from measured bed thicknesses may lead to inaccurate interpretations and correlations (Martin-Chivelet et al., 2000). Boss and Rasmussen (1995) demonstrated the limitations of the use of Fischer plots as sea-level curves.

Pittet (1994) introduced a method to calculate amplitudes of short-term and long-term sea-level history using equations involving sediment accumulation, subsidence, and sea-level variation. His model depends on a detailed cyclostratigraphic and time framework. Symmetric and asymmetric sea-level changes and decompaction are integrated, but only one theoretical case for the interaction of accumulation rate and sea-level change is incorporated. Like Fischer plots, this approach is restricted to successions where accommodation space is filled during every sea-level cycle. However, in many shallow-marine carbonate successions this latter criterion is not fulfilled, so a satisfactory quantitative analysis of accommodation and sea-level changes cannot be accomplished with the existing models. Tipper (2000) advanced a theoretical quantitative model relating changes in sediment budget and accommodation and illustrated the resulting complexity of stratigraphic patterns. However, his work cannot easily be applied to real-world depositional sequences measured in the field.

In order to assess quantitatively sedimentary processes in shallow carbonate systems, smallscale changes in accommodation, sediment production and accumulation rates, and water depth have to be evaluated. This knowledge is essential for a detailed understanding of carbonate production potential, sediment accumulation, and sediment fluxes across the platform and from platform to basin.

Since very few carbonate successions are entirely peritidal with a repetitive infill of accommodation space, a model considering different combinations of accumulation rate and sea-level change, including pure subtidal cycles, is put forward here. The advantage of the model is that it is based on sediment thicknesses measured in the field, and interpretations derived from a detailed facies and cyclostratigraphic analysis. It is therefore applicable to a variety of shallow-marine carbonate successions that show a cyclic pattern of facies evolution through time. First, we present the theoretical background of the model, then we apply it to the shallow carbonate platform of the Middle Berriasian to Lower Valanginian in the French Jura Mountains.

\section{Theoretical background}

\subsection{Definitions}

The term depositional sequence applied in this study follows the definition of Strasser et al. (1999) and is independent of scale (Posamentier et al., 1992). It represents the stratigraphical record of one cycle of relative sea-level change and is often referred to as a 'sedimentary cycle' in the literature. The small-scale depositional sequences typical of carbonate platforms commonly are delimited by discontinuity surfaces or rapid facies changes (Hillgärtner, 1998). According to facies evolution implying changes in water depth, they are commonly composed of deepening-upwards, 
lowstand to transgressive deposits and shallowing-upwards, highstand deposits (Fig. 1). Following the sequence-stratigraphic nomenclature of Vail et al. (1991), their lower and upper bounding discontinuities are called sequence boundaries (SBs). If lowstand deposits are absent, the SBs coincide with transgressive surfaces (TS). The surface or interval representing maximum water depth is called maximum flooding surface (MF, Fig. 1).

\subsection{Decompaction}

Preserved thickness of depositional sequences is a very inaccurate proxy for accommodation and may not be representative at all in many cases, especially those within icehouse periods (e.g. the Holocene of the Bahamas; Boss and Rasmussen, 1995). It is therefore essential to correct for differential compaction of a sedimentary succession before any further interpretations are made, if it consists of heterogeneous facies that undergo different volume changes during burial.

A number of different decompaction algorithms that relate different lithologies to specific depthporosity curves have been proposed (e.g. Sclater and Christie, 1980; Bond and Kominz, 1984;
Goldhammer, 1997). In order to decompact individual small-scale depositional sequences, the vertical distribution of the different lithofacies and the thickness of the overlying stratigraphic column have to be known. Goldhammer (1997) demonstrated that, in mud-supported carbonates at least, most compaction occurs during shallow burial with 100-400 m overburden. As a measure, the decompaction factor (D) representing the ratio between the initial depositional thickness and the present-day (compacted) thickness, was introduced (Baldwin, 1971). Decompaction factors of 1-1.2 for carbonate sand and 2-2.5 for carbonate mud are generally realistic in shallow to medium burial depths; marls and shales can attain higher numbers between 3 and 5 (Shinn and Robbin, 1983; Moore, 1989; Goldhammer, 1997).

The Dunham classification reflects the relative abundance and packing of grains and mud in a carbonate rock, so the behaviour of each texture during burial is represented by decompaction factors. The decompaction factors used in this study lie between 1.2 for pure carbonate sand, 2.5 for pure carbonate mud, and 3.0 for marls (Fig. 1). Maximum burial depth of less than $1000 \mathrm{~m}$ can be assumed for the Jura platform (Trümpy, 1980). Decompacted thicknesses of lowstand-to-trans-

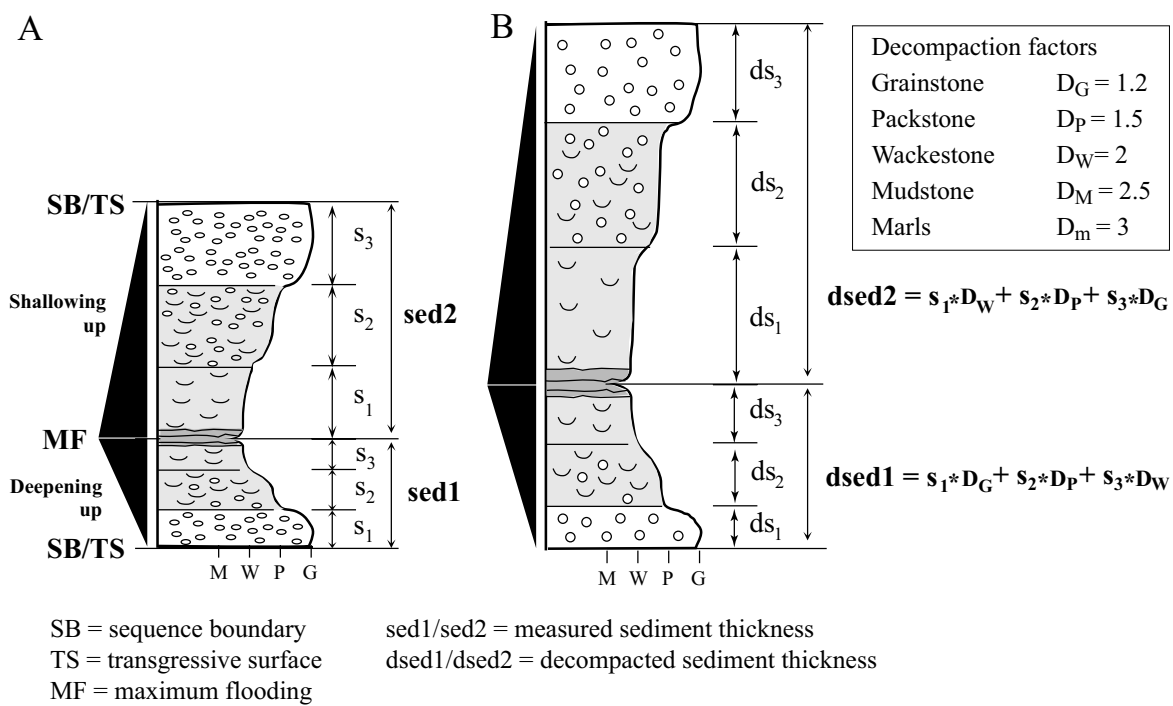

Fig. 1. Decompaction of a small-scale depositional sequence representing one cycle of relative sea-level change. (A) Measured thickness of different sediment textures (s1-s3) in lowstand/transgressive deposits (sed1) and highstand deposits (sed2) of a depositional sequence. (B) Decompacted thickness (dsed1/dsed2) calculated with indicated decompaction factors. 
A

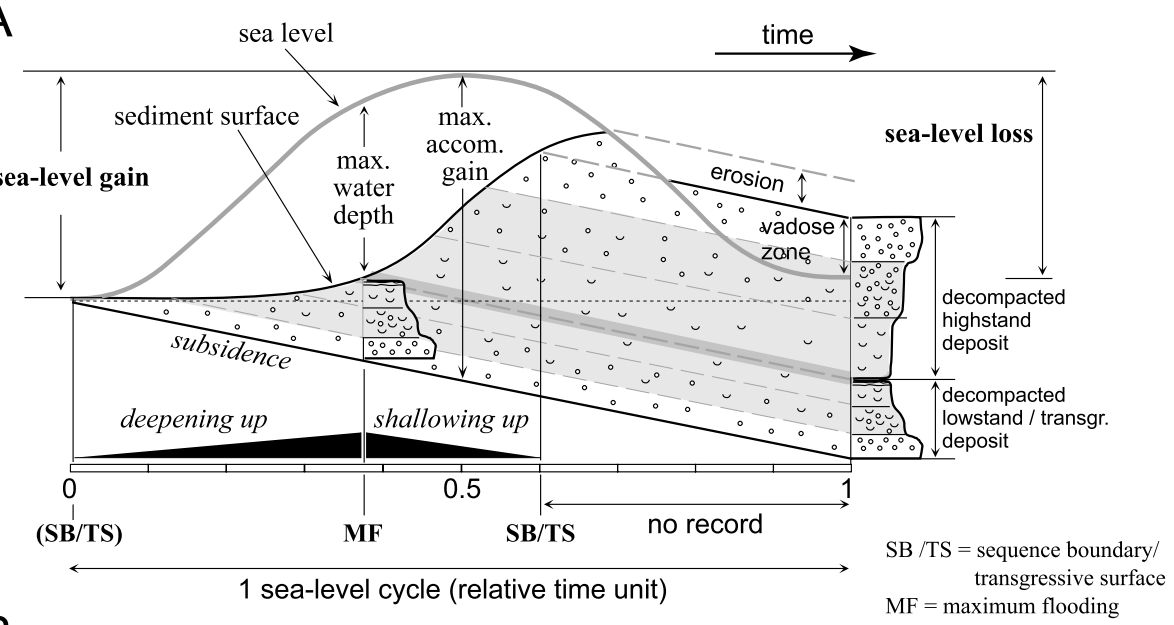

B

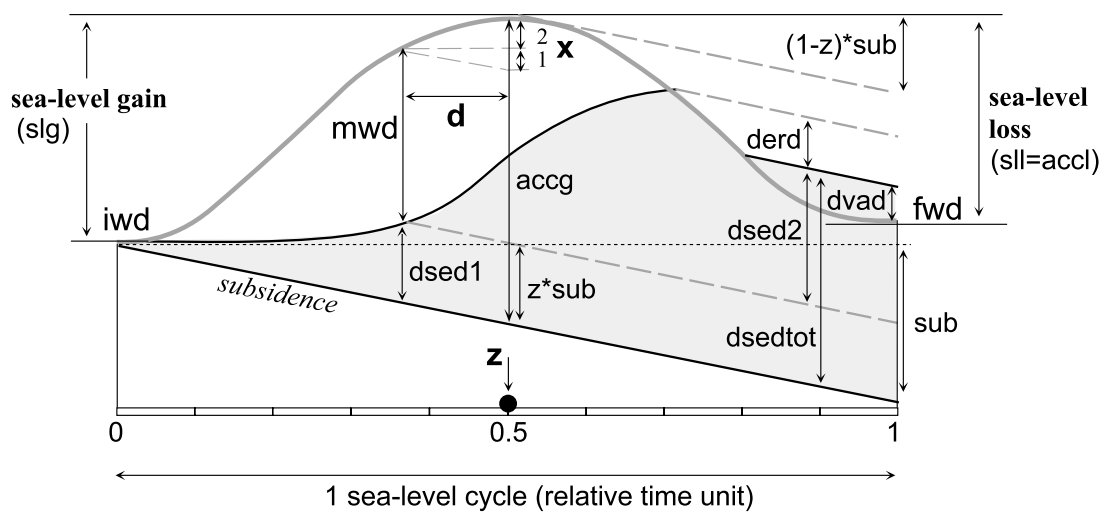

\section{VARIABLES}

sedtot $=$ total sediment thickness of one dep. sequence

sed1 $=$ sedimet thickness between $\mathrm{SB} / \mathrm{TS}$ and MF

sed2 = sediment thickness between MF and SB/TS

$\Xi \mathbf{v a d}=$ thickness of the vadose zone

iwd $=$ initial water depth $(\mathrm{m})$

mwd = maximum water depth (m, at "maximum flooding")

fwd = final water depth $(\mathrm{m})$

sub $=$ mean subsidence in $\mathrm{m}$ per depositional sequence

derd $=$ decompacted thickness of eroded sediment

$\mathbf{d}=$ distance between maximum water depth and maximum accommodation gain (in relative time units)

$\mathbf{z}=$ position of maximum accommodation gain (measure for the asymmetry of the sea-level curve)

dsed1 $=$ differentially decompacted thickness of sed 1

dsed2 $=$ differentially decompacted thickness of sed2

dvad $=$ differentially decompacted thickness of vadose zone

D. dsedtot $=$ total (decompacted) sediment thickness

$\mathbf{x}=$ correction factor for difference between accommodation at MF and accg

made up of $x 1$ and $x 2$ :

ठ $\mathbf{x} 1$ = attributable to continued subsidence

$\mathbf{x 2}=$ attributable to the relation of $\mathrm{d}$, rate of sea-level change,

and general amplitude of sea-level cycle

accg = maximum accommodation gain

slg $=$ sea-level gain

accl, $\mathbf{s l l}=$ accommodation loss, which equals sea-level loss

\begin{tabular}{lll|}
\hline Water depth ranges $(\mathrm{m})$ & & \\
1. emersive/intertidal: & $\min -0.5$ & $\max 0.5$ \\
2. very shallow: & $\min 0.5$ & $\max 2$ \\
3. shallow & $\min 2$ & $\max 5$ \\
4. deep: & $\min 5$ & $\max 10$ \\
5. very deep: & $\min 10$ & $\max 20$
\end{tabular}

$\mathbf{s}_{1} * \mathbf{D}_{\mathbf{m}}+\mathbf{s}_{\mathbf{2}} * \mathbf{D}_{\mathbf{M}}+\mathbf{s}_{\mathbf{3}} * \mathbf{D}_{\mathbf{W}}+\mathbf{s}_{\mathbf{4}} * \mathbf{D}_{\mathbf{P}}+\mathbf{s}_{\mathbf{5}} * \mathbf{D}_{\mathrm{G}}$ $s_{1} * D_{m_{1}}+s_{2} * D_{M}+s_{3} * D_{W}+s_{4} * D_{P}+s_{5} * D_{G}$ $s_{1} * D_{m}+s_{2} * D_{M}+s_{3} * D_{W}+s_{4} * D_{P}+s_{5} * D_{G}$ dsed1 + dsed2

$d^{*}$ sub

$\left(d^{2 * 3}\right) *($ dsed1 $1+$ mwd $-($ sub $*(z-d)))$

dsed $1+m w d+x_{1}+x_{2}$-iwd

accg-z*sub

accg $+\left((1-z)^{*}\right.$ sub $)-($ dsedtot + fwd + dvad $)$ 
gressive deposits and highstand deposits are calculated separately, since each value will be needed in later calculations.

\subsection{Characterisation of a depositional sequence}

Depositional sequences are the stratigraphical expression of the interaction of two major controlling factors: sediment-accumulation rate and rate of accommodation change, defined by rates of sea-level change and subsidence (cf. Schlager, 1993; Tipper, 2000). One possible interaction between these three variables during one sea-level cycle is illustrated in a 1-D model using a quasisinusoidal sea-level curve, a curve representing the sediment surface, and a linear subsidence trend (Fig. 2A). Linear subsidence trends are approximations of the long-term average, but are assumed to be realistic for short-time intervals in the order of tens to a few hundreds of thousand years. Time is represented on the $x$-axis in units of a complete sea-level cycle. Fig. 2A shows a case where accumulation rate lags behind an initial sea-level rise (Tipper, 1997), which results in a deepening-up trend of sedimentation. The point in time when this trend is reversed (accumulation rate exceeds the rate of sea-level rise) coincides with MF. Here the deepest facies is recorded. A shallowing-up trend in facies represents the time interval from the MF to the point where falling sea level exposes the sediment surface and may result in erosion. Here a SB will form. If early cementation stabilises the sediment and sea level continues to fall, a vadose zone develops with dissolution.

A few simple but important rules can be derived from such 1-D models, which have been widely used to describe the balance between accumulation and accommodation (e.g. Read et al., 1986; Strasser, 1994; Sadler, 1994; Tipper, 2000). First, the sedimentary record of one depo- sitional sequence typically represents only part of the sea-level cycle, in this case only $60 \%$ (Fig. 2A). However, information about the amplitude of the sea-level drop below the sediment surface can be obtained through depth of erosion and/or the thickness of the vadose zone. A second observation is that transgressive deposits and highstand deposits represent different time spans that are controlled by changes in accumulation rates. A third and very important conclusion is that the time corresponding to the maximum of water depth (mwd) recorded in the facies does not correspond to the time $(\mathrm{z})$ when the maximum accommodation gain $(\mathrm{accg})$ is reached (at 0.5 time units in Fig. 2A). Consequently, a true 'eustatic' sea-level curve must be corrected for this difference.

The variables that are needed to calculate sealevel gain and loss can be derived geometrically from the 1-D model (Fig. 2B). The explanation of the variables and the formulae needed to calculate them are indicated in Fig. 2C. Three types of variables are used. The first type includes thicknesses measured in the field: thickness of the different facies in lowstand to transgressive and highstand deposits of one depositional sequence, and thickness of the vadose zone where present.

The second type of variable is based on a detailed facies and stratigraphic analysis. Initial, maximum and final water-depth ranges are estimated according to facies (Fig. 2C). The initial water depth of a depositional sequence is the same as the final water depth of the preceding depositional sequence. The thickness of the eroded sediment has to be estimated for each depositional sequence according to features such as channelling, reworking, or palaeosol formation. The time between maximum flooding and maximum accg $(d)$ has to be estimated, and the time at which the maximum accg occurs has to be determined. Here, different combinations of sea-level

Fig. 2. The relationship of sea level, sediment-accumulation rate, and subsidence rate during one quasi-symmetrical sea-level cycle. (A) Relation of the three variables within the observed deposits. (B) Geometrical variables that describe the relationship of sea level, sediment surface, and subsidence. (C) Interpreted and calculated variables needed to deduce 'real' sea-level gain and loss during one sea-level cycle. Decompaction ratios as detailed in Fig. 1. 
and accumulation curves are used in order to approximate the variability inherent in a natural sedimentary system (see Sections 2.4 and 2.5).

The third type of variable is calculated from the previously measured and interpreted ones. Decompacted thicknesses are obtained using the ap- propriate decompaction factors (Fig. 1). The variable describing the vertical distance $(x)$ between accg at the MF and the maximum accg is calculated in two steps: one part $\left(x_{1}\right)$ is a function of $d$ (relative time unit) and subsidence, the other part $\left(x_{2}\right)$ can be roughly described as a function of $d$,
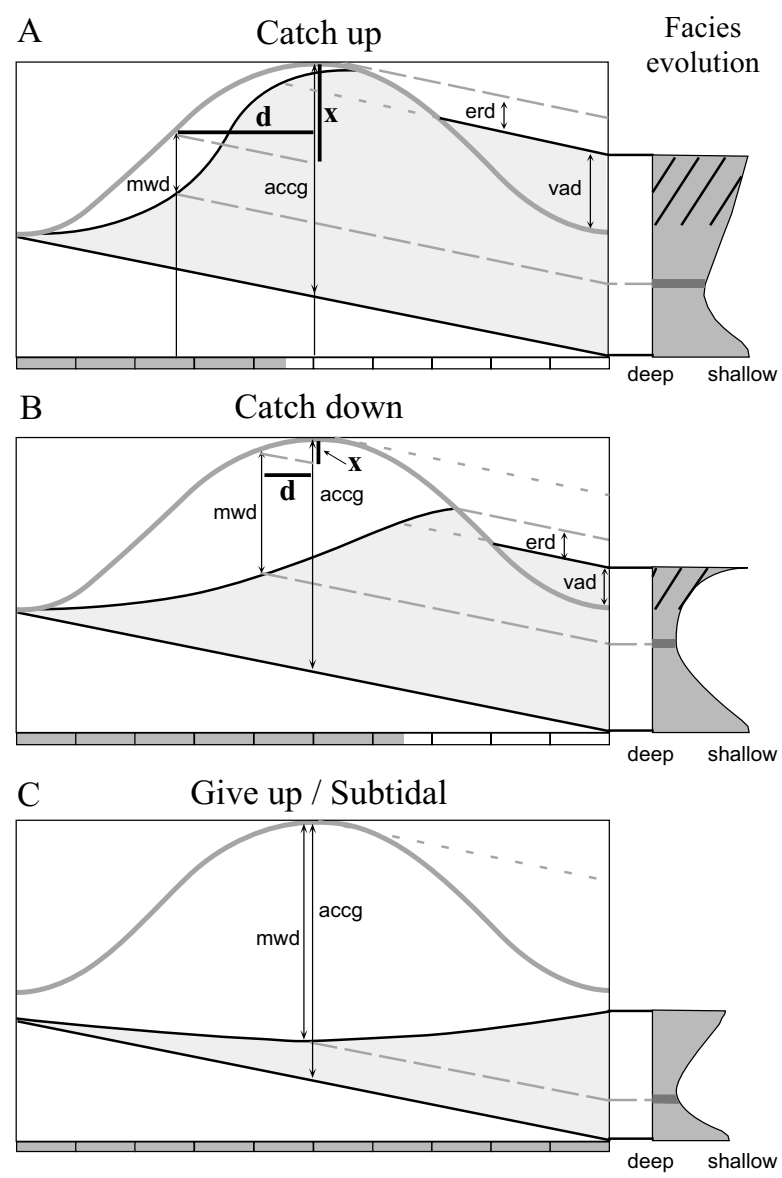

D $\quad$ Keep up

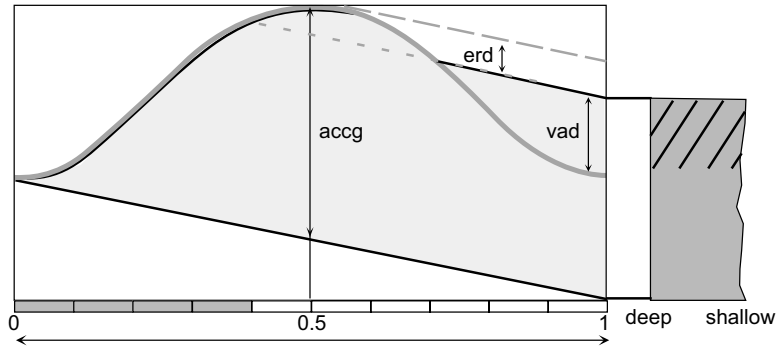

1 sea-level cycle (relative time unit)

relative time of one cycle recorded with deposition relative time of one cycle without depositional record 
the rate of sea-level change, and the amplitude of the sea-level gain at MF (Fig. 2B,C). The relation of $d$ with the exponentially decreasing rate of sealevel change towards the point of maximum accommodation is described with the simple function $\left(d^{2}\right)$ and scaled empirically for amplitude with the factor 3. Finally, maximum accg, accommodation loss, and net sea-level gain and loss for one cycle can be calculated (Fig. 2C).

It is evident that these estimations and calculations include big error margins, and that this model represents an oversimplification of a realworld sedimentary system reacting to a sea-level cycle. In order to make better approximations of conditions on a shallow carbonate platform, several types of sedimentary cycles and several trends of long-term sea-level evolution must be considered.

\subsection{Sequence types}

We have described thus for one possible model the interaction of accommodation and accumulation. A number of different interaction patterns of these variables are possible, resulting in a variety of hypothetical stratigraphic cycles (Tipper, 2000). Soreghan and Dickinson (1994) defined five generic cycle types on the basis of differences in facies evolution and completeness of the facies succession. In our study of shallow-water carbonates, four of these main cycle types are distinguished and can be referred to the terminology of Kendall and Schlager (1981) (Fig. 3).

(1) 'Catch-up' sequences: accumulation rate initially lags behind the creation of accommodation space, but during highstand conditions progressively outpaces sea-level rise and fills most of the available space. The resulting facies evolution shows a deepening-up, then shallowing-up trend (Fig. 3A). The shallowing-up facies evolution of the highstand is continuous and not interrupted. Erosion and/or vadose diagenetic overprint are common in these sequences. Note the large distance and difference in amplitude between the maximum water depth recorded in the facies and the point of maximum accommodation.

(2) 'Catch-down' sequences are characterised by a lag time of sediment accumulation with respect to accommodation rate, and an intersection of the two curves in the late highstand on the falling leg of the sea-level curve (Fig. 3B). Facies evolution shows a gradual deepening, followed by an incomplete shallowing succession with supratidal facies or vadose diagenesis directly overlying or overprinting subtidal facies.

(3) 'Give-up' sequences represent a carbonate factory that cannot keep up or catch up with the rising sea level (Fig. 3C). Commonly, these sequences show deepening, then shallowing trends but are not bounded by subaerial exposure surfaces and are composed entirely of subtidal facies. They compare to the 'subtidal cycles' described by Osleger (1991).

(4) 'Keep-up' sequences have not been observed in this study but are included in the classification for the sake of completeness (Fig. 3D). They represent a dynamic equilibrium between accommodation rate and sedimentation rate with no lag time, which results in a purely aggradational succession completely filling the created space. Facies

\footnotetext{
Fig. 3. Four cases of different facies evolution reflecting variable accumulation rates with respect to amplitude of sea-level variation and subsidence rate. (A) The 'catch-up' sequence with a gradual shallowing-up facies evolution represents a slow catch up of sediment accumulation with sea-level rise after a maximum flooding (mwd). Almost the entire accommodation space is filled and erosion and subaerial exposure may represent significant parts of the cycle. (B) The 'catch-down' sequence reflects a drop of sea level onto the sediment surface. Facies evolution, therefore, shows an abrupt or rapid shallowing-up trend with thin shallowwater facies capping deeper water sediments. C) 'give-up/subtidal' sequences show a gradual deepening and shallowing of facies, but subaerial exposure never occurs. Note the variability of $d$ (distance between maximum water depth and maximum accg) and $x$ (the correction factor for the calculation of the maximum accg) in the three cases. (D) 'Keep-up' sequences represent a rare case of equilibrium between accumulation rate and change in accommodation. The sediment surface keeps up exactly with sealevel rise and thus sediment fills the entire available space. Consequently, maximum accg equals the decompacted sediment thickness (dsedtot) plus the erosional depth (erd).
} 
continuously indicate very shallow conditions. Erosion and diagenetic overprint are likely to occur during sea-level fall.

\subsection{Symmetry-asymmetry and long-term sea-level trends}

The 1-D models for the different sequence types are based on a quasi-sinusoidal shape of the sealevel curve. Short-term sea-level variations that are largely induced by glaciation-deglaciation cycles have a markedly asymmetric form (e.g. Shackleton, 1987). However, in the Early Cretaceous, there is no evidence for a dominant control of high-frequency sea-level changes by glacial processes. Orbitally-induced insolation changes probably translated more or less directly into sea-level changes by thermal expansion and retraction of the uppermost layer of ocean water (Gornitz et al., 1982), by thermally-induced volume changes in deep-water masses (Schulz and Schäfer-Neth, 1998), and/or by water retention and release in lakes and aquifers (Jacobs and Sahagian, 1993). Studies by Pittet (1994) in the Oxfordian of the Swiss Jura showed that symmetrical small-scale sea-level changes are the most likely explanation for the observed accommodation changes. However, even if a sinusoidal sea-level curve may serve as a proxy for a 'true' eustatic sea-level change, the superposition of such high-frequency changes

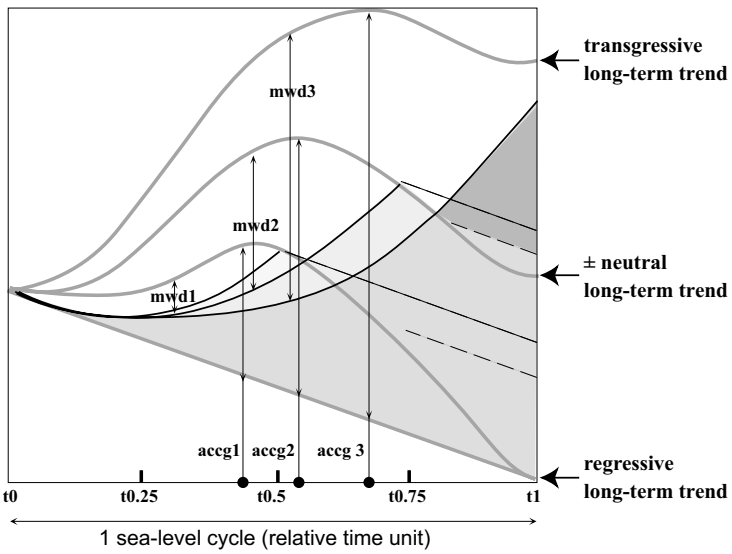

Fig. 4. Superposition of small-scale sea-level variations on a longer term trend causes asymmetry of the sea-level curve. Maximum flooding and maximum accg, therefore, occur at different relative times during each sea-level cycle. on a long-term trend of sea level introduces a certain degree of asymmetry (Fig. 4). Consequently, the points in time when maximum flooding and maximum accg are attained shift accordingly.

A long-term transgressive trend is assumed where the thicknesses of several successive depositional sequences exceed the average sequence thickness of the entire studied succession by more than $25 \%$. When the thickness is $25 \%$ smaller than the average thickness, a long-term regressive trend is assumed. As long as the values remain within $\pm 25 \%$ of the average, the long-term sea level is considered to have been more or less stable.

Interaction of the three different long-term trends with the three sequence types recognised in this case study results in nine possible combinations, each with different characteristics in terms of position of mwd and maximum accg within one sea-level cycle (Fig. 5). These combinations are used to define minimum and maximum values for $d$, the variable describing the relative time between the mwd and accg, and $z$, the position of accg within the sea-level cycle. For ranges and typical values used in the calculations refer to Fig. 5. Keep-up sequences add a tenth combination, in which mwd is zero and accg independent of the long-term trend of sea-level evolution. Sequence thickness plus erosion depth thus define accg (Fig. 3D).

\subsection{Implementation}

The calculation of the 'sea-level curves' corresponding to the measured sections is easily carried out as spreadsheet operations in standard software. Variables and formulae used to calculate the curves are documented in Fig. 2. Three different sea-level curves are generated for each succession of depositional sequences. Two curves are calculated using first all maximum values, then all minimum values of variables expressed as ranges. The mean of these two curves is then used for further calculations. Feedback provided by the model helps to filter out impossible situations which can occur using ranges, rather than one value in the calculations. These include, for 
Long term sea-level trend
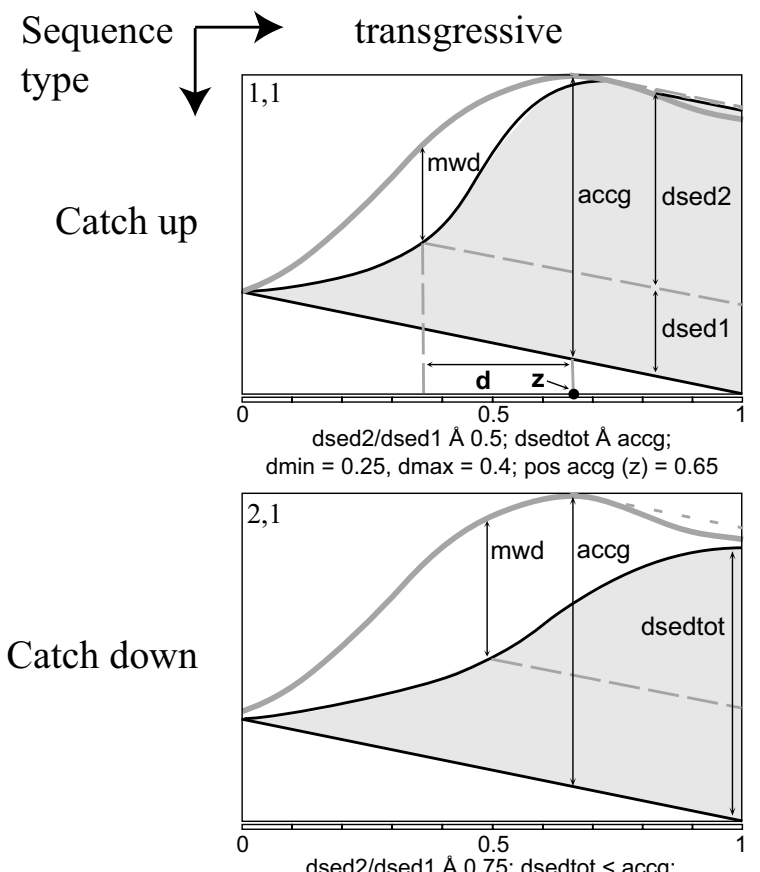

dsed2/dsed1 $\AA$ 0 0.75; dsedtot < accg

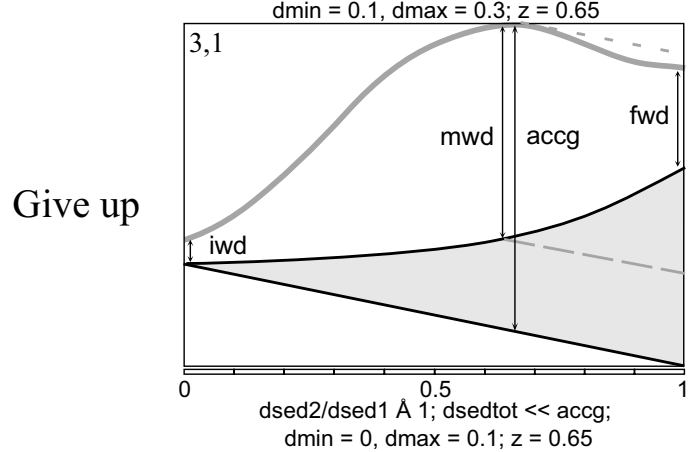

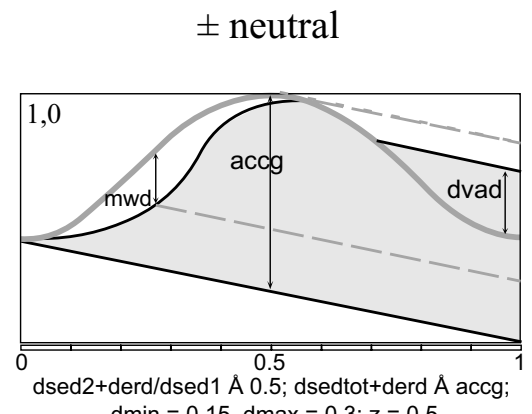

$\mathrm{dmin}=0.15, \mathrm{dmax}=0.3 ; z=0.5$

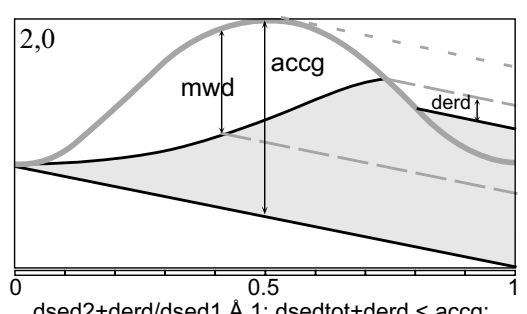

dsed2+derd/dsed1 $\AA$ 1; dsedtot+derd < accg; $\mathrm{dmin}=0.05, \mathrm{dmax}=0.2 ; \mathrm{z}=0.5$

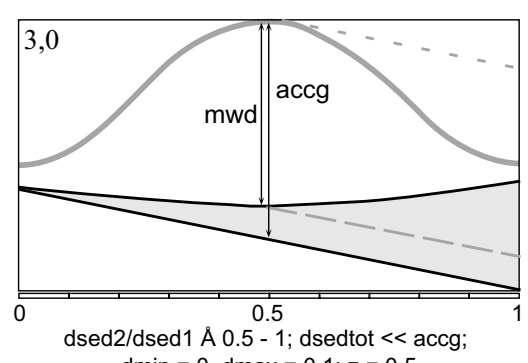
dsed $A$. $0.5-1$, dsedtot $<<$ accg; regressive

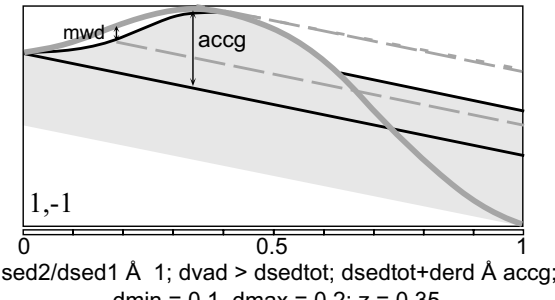
$d \min =0.1, d \max =0.2 ; z=0.35$

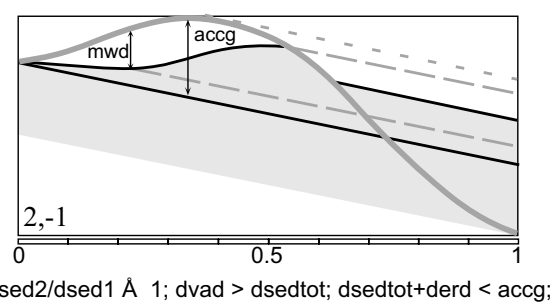
$\mathrm{dmin}=0.1, \mathrm{dmax}=0.2 ; z=0.35$

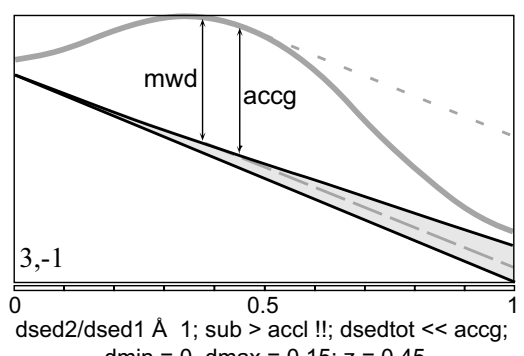
$\mathrm{dmin}=0, \mathrm{dmax}=0.15 ; z=0.45$

Fig. 5. Nine combinations of three sequence types with different trends in long-term sea level. For each combination minimum and maximum values for $d$ and the position of the maximum accg $(z)$ are estimated in relative time units. 9 
example, cases where the calculated accg is less than the decompacted thickness of the depositional sequence or where the calculated minimum values exceed calculated maximum values.

\section{Case study}

\subsection{Study area and interval}

The methodology described in earlier sections is applied to the Middle Berriasian to Lower Valanginian carbonate platform deposits of the French Jura (Fig. 6). A detailed facies and cyclostrati- graphical analysis was undertaken on nine sections selected to cover the Pierre-Châtel, Vions, and Lower Chambotte Formations (Clavel et al., 1986) as completely as possible (Hillgärtner, 1998, 1999; Strasser and Hillgärtner, 1998). Six of these sections are included in the present analysis (Fig. 6A). The time interval of the sections covers about 5 million years according to global sequence and chronostratigraphic charts (Fig. 6B). Biostratigraphic markers include ammonites, calpionellids and benthic foraminifera, all correlated with the regional ammonite stratigraphy (cf. Strasser and Hillgärtner, 1998; Hillgärtner, 1999).
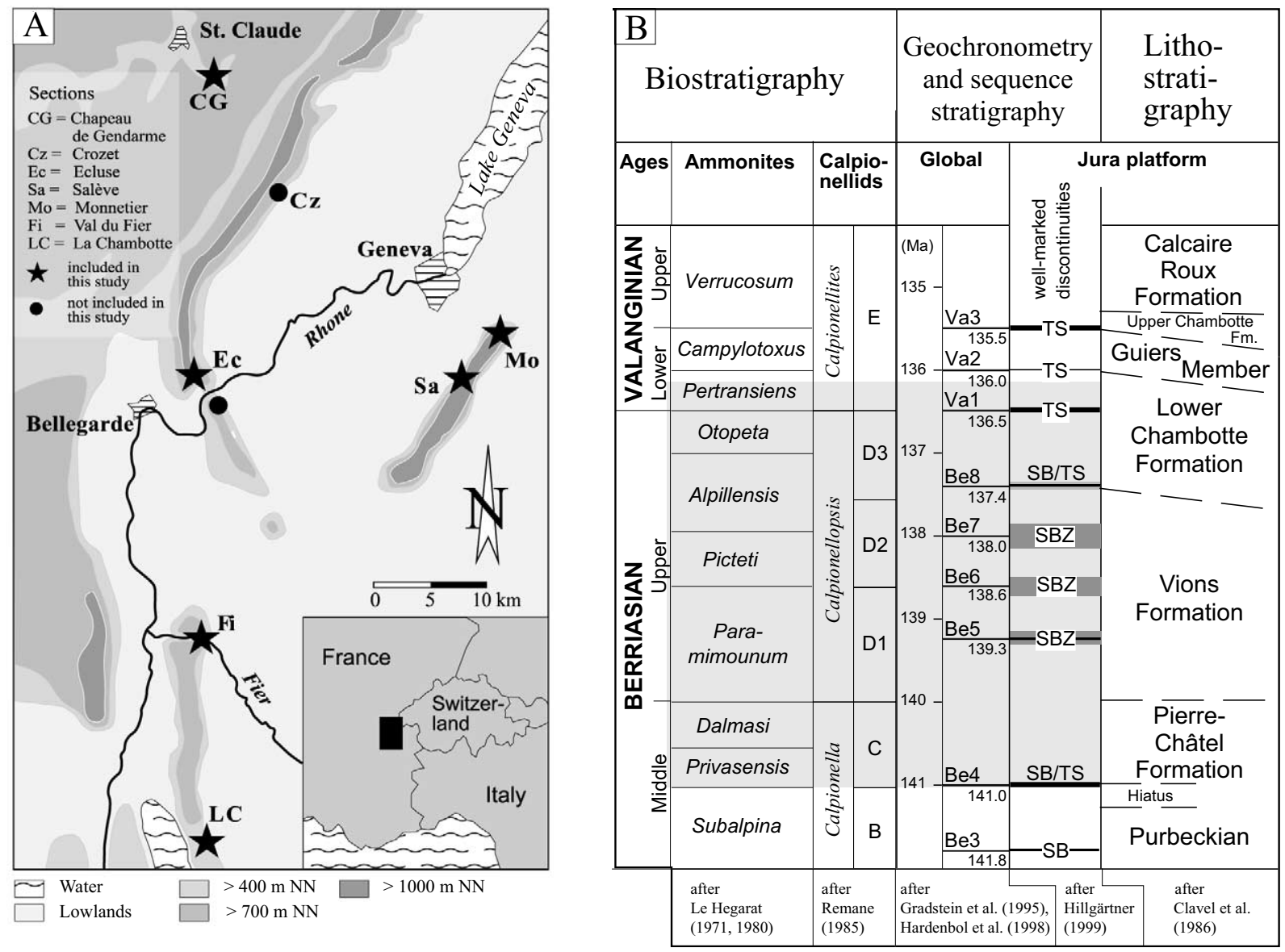

Fig. 6. (A) Study area. (B) Study interval (shaded). Be3-Va3 are major 'third-order' SBs identified by Hardenbol et al. (1998). Well-expressed discontinuity surfaces and zones of surfaces corresponding to SBs, TS, and sequence-boundary zones (SBZ) observed in the study area correlate well with the 'global' sequence-stratigraphic scheme (data from; Le Hégarat, 1971, 1980; Remane, 1985; Gradstein et al., 1995; Hardenbol et al., 1998; Hillgärtner, 1999; Clavel et al., 1986). 


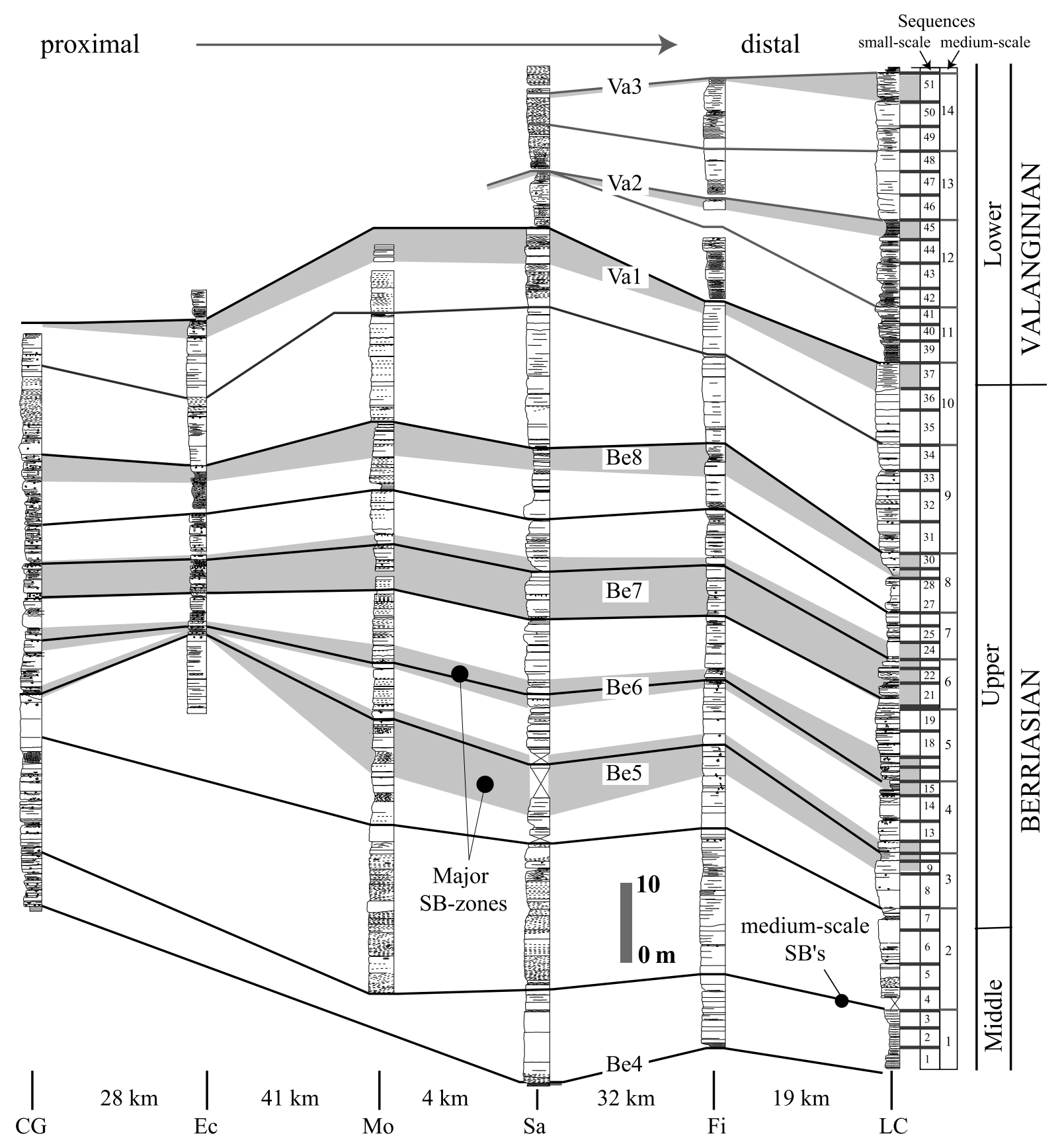

Fig. 7. Correlation of different hierarchies of depositional sequences in key sections of the study area. Medium-scale depositional sequences and major sequence-boundary zones are correlated across. Small-scale sequences are indicated at the right side of the graph only, but not all are accounted for by number due to local condensation and for reasons of clarity. For location of the sections see Fig. 6A. 


\subsection{Database}

Facies analysis of the sections utilised about 1800 rock samples and 1200 thin sections. Marls and clays were washed and sieved, and grain-size fractions analysed under the binocular microscope for relevant microfossils. Stable-isotope analysis in selected sections was used to identify the diagenetic imprint of subaerial exposure (Hillgärtner, 1998, 1999). Water-depth estimates are based on standard analysis and interpretation of microfacies associations, sedimentary structures and early-diagenetic signatures (Hillgärtner, 1999).

\subsection{Sequence and cyclostratigraphic analysis}

The sections were interpreted in terms of highresolution sequence stratigraphy and cyclostratigraphy. The terminology and concepts used are described in Strasser et al. (1999).

Several hierarchies of depositional sequence can be identified and correlated throughout the study area (Figs. 7 and 8). 'Major sequence-boundary zones' are sections where discontinuity surfaces are best expressed (Hillgärtner, 1998). These zones correlate well with the 'third-order' SBs defined by Hardenbol et al. (1998) in European basins (Fig. 6B). 'Small-scale depositional sequences', commonly between one and a few metres thick, typically comprise 3-6 beds, which form the essential building blocks of the successions. These display facies evolutions corresponding to one environmental cycle and thus qualify as 'elementary sequences' (Strasser and Hillgärtner, 1998). Medium-scale sequences are composed of several small-scale sequences that commonly show wellmarked deepening-shallowing trends (Strasser et al., 1999; Fig. 8A).

Biostratigraphic tie points provide estimates of the duration of the successions (Fig. 8B). These time intervals divided by the number of elementary, small-scale and medium-scale sequences identified in the measured sections yield durations that fall within the Milankovitch frequency band. The small-scale and medium-scale sequences are interpreted to correspond to the first and second eccentricity cycles with durations of $100 \mathrm{ky}$ and $400 \mathrm{ky}$, respectively, and the elementary sequences are thought to reflect the precession cycle of $20 \mathrm{ky}$ (Berger et al., 1989). Furthermore, the observed hierarchical stacking of depositional sequences corresponds to the hierarchy expected for Milankovitch cyclicity. Thus, we assume that elementary, small-scale and medium-scale depositional sequences are related to sea-level fluctuations controlled by orbital insolation cycles (e.g. Strasser and Hillgärtner, 1998). This interpretation is fairly consistent with the sequence-chronostratigraphic framework given by Hardenbol et al. (1998) (see Strasser and Hillgärtner, 1998; Hillgärtner, 1999).

Facies contrasts in the elementary sequences are generally too small to be used for the calculations mentioned above. Small-scale sequences, however, are well developed, and their facies evolutions permit the application and testing of our model. Forty small-scale (100-ky) sequences that can be correlated across the platform are analysed in this study (sequences 1-40; Fig. 7). These sequences are classified according to the different types described above (Figs. 3 and 8B). Keep-up sequences have not been identified.

\section{Results}

\subsection{Changes in sea level}

For each of the six analysed sections, minimum, maximum and mean sea-level curves are calculated with the method outlined above (Fig. 9). An additional curve showing the mean interpreted water depth is also illustrated (Fig. 10A). For all sections, a mean subsidence rate of $3 \mathrm{~m} / 100 \mathrm{ky}$ is assumed for the initial calculations. This value is an average for the passive-margin setting of the Jura platform in the Early Cretaceous, where differential subsidence played an important role (Wildi et al., 1989). In the Salève section an initial longer-term sea-level rise was followed by a phase when small-scale oscillations with variable amplitudes dominated (Fig. 11A). Towards the end of the succession, long-term sea level rose again. High-frequency changes in sea-level amplitude are best expressed in the curve calculated with minimum values, whereas the curve based on 

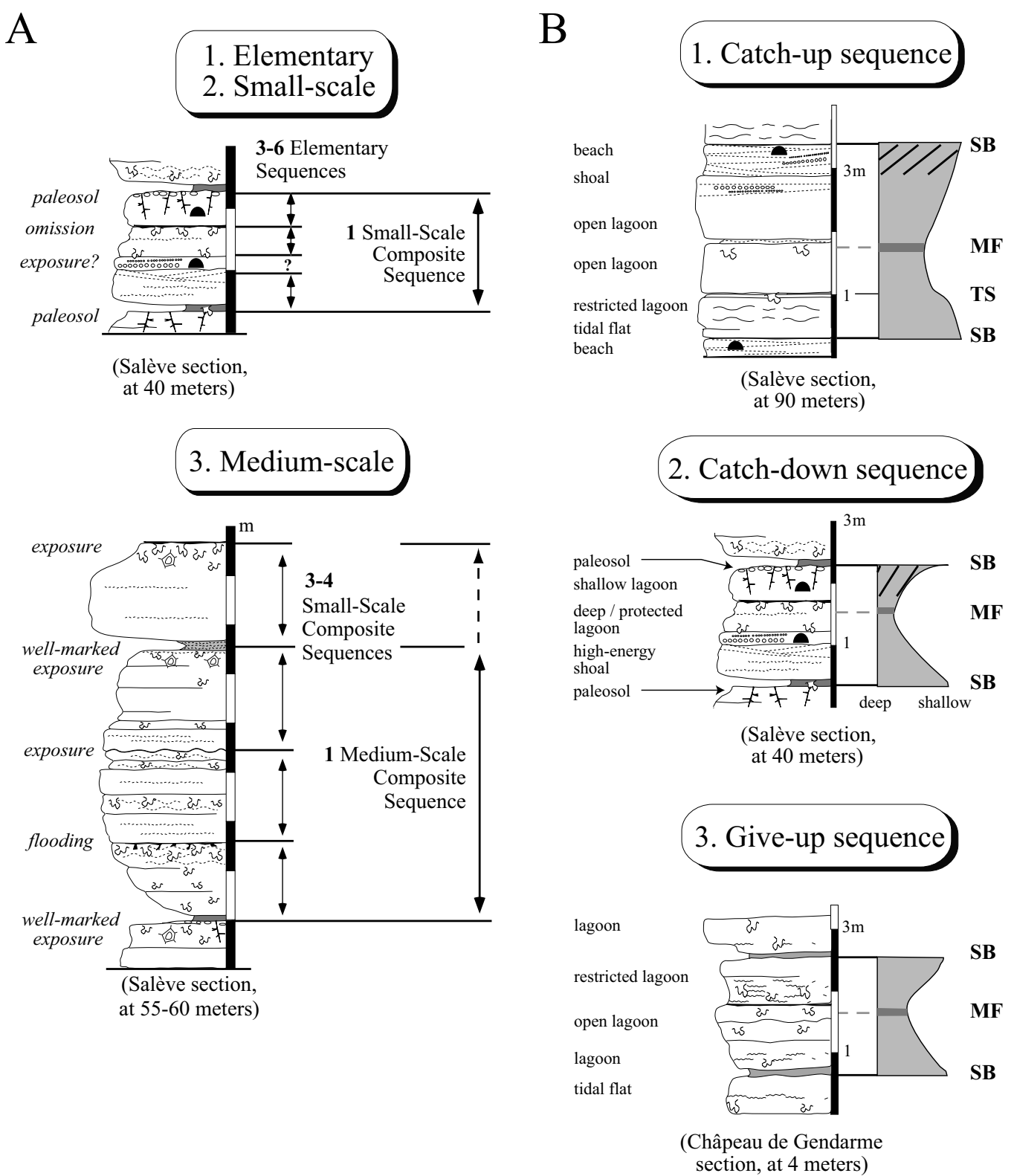

Fig. 8. (A) Different hierarchies of depositional sequences in the study area. (B) Examples of the different types of depositional sequences in the study area. Symbols shown in legend of Fig. 9.

maximum estimates appears to be slightly flattened. This is mainly due to the differences in interpreted water-depth ranges.

A traditional Fischer plot for the same measured section is presented in Fig. 10B. This plot also shows that initially the depositional sequences are thicker than average, followed by a signifi- cant decrease in average thickness. Only towards the end of the curve, a slight increase of average thickness and, thus, accommodation is indicated. Although this general trend of accommodation change is consistent with interpretations that can be derived from our calculated sea-level curve, the difference in the shape of the curves is obvious. 
La Chambotte

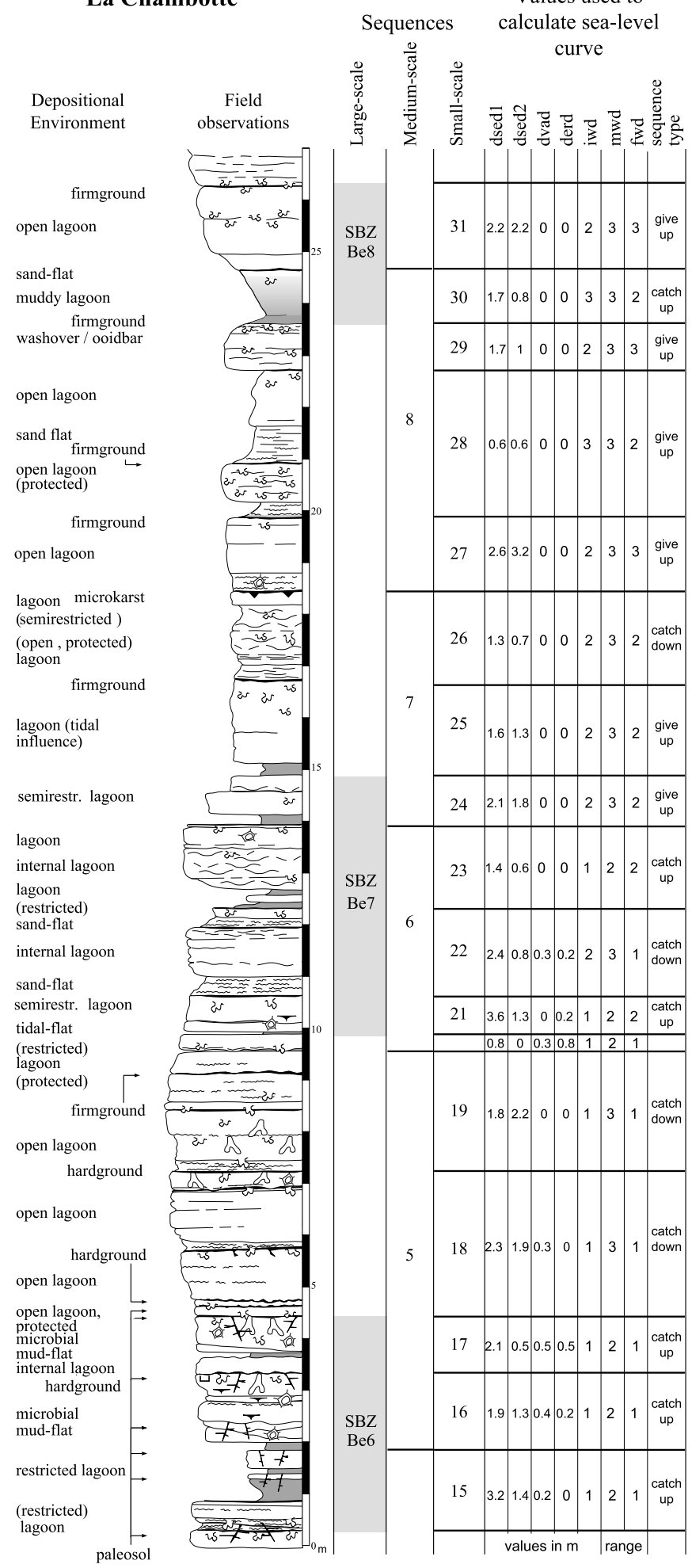

\begin{tabular}{|c|c|c|c|}
\hline \multicolumn{4}{|c|}{ Legend } \\
\hline as is & $\begin{array}{l}\text { Bioturbation } \\
\text { undifferentiated }\end{array}$ & $\frac{7}{r}$ & $\begin{array}{l}\text { Root casts } \\
\text { Paleokarst }\end{array}$ \\
\hline$a$ & Thalassinoides & - & Bioperforation \\
\hline or & Desiccation cracks & 00000000000 & $\begin{array}{l}\text { Laminations } \\
\text { (fining-up) }\end{array}$ \\
\hline$\overline{0}$ & $\begin{array}{l}\text { Fenestrae } \\
\text { Keystone vugs }\end{array}$ & & Nodular bedding \\
\hline
\end{tabular}



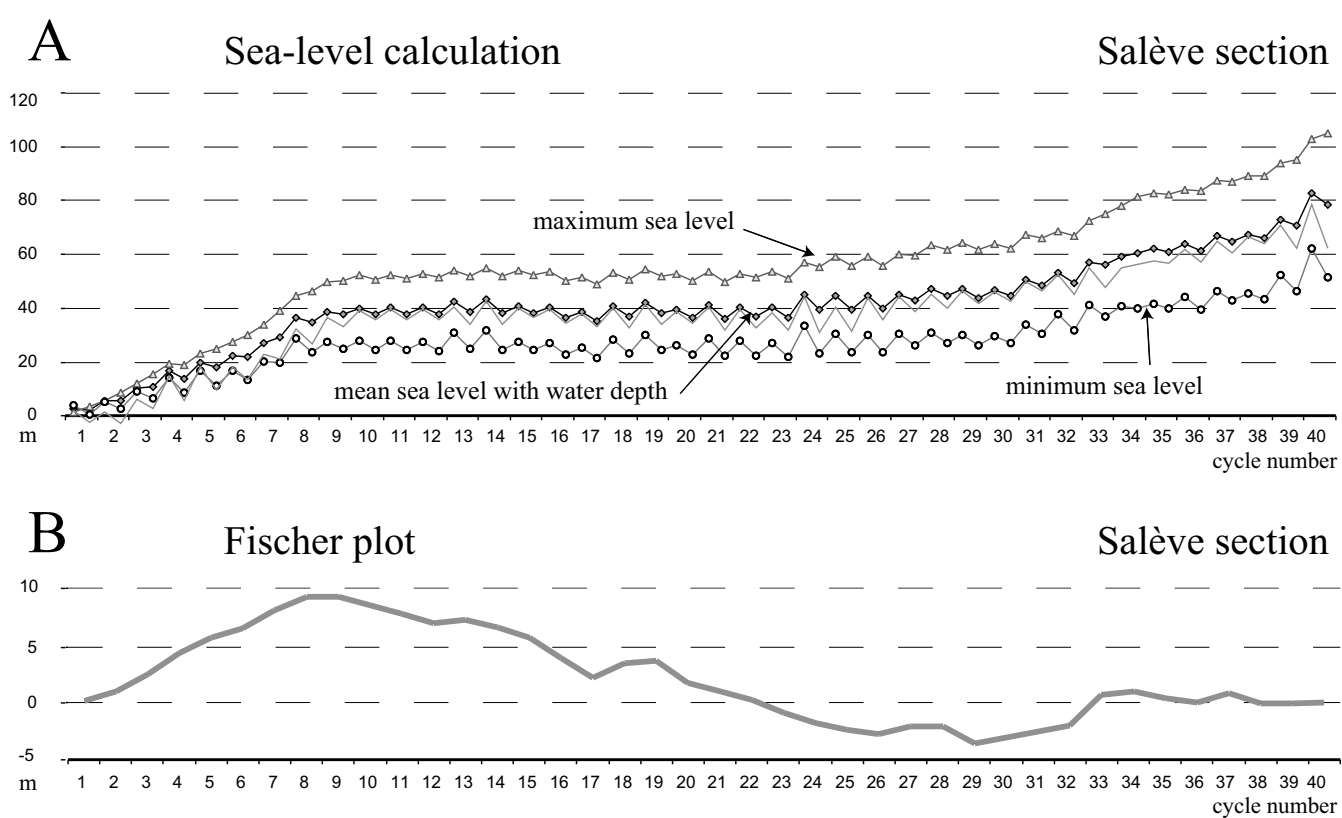

Fig. 10. (A) Calculation of sea level with minimum, maximum and mean values for the same interval. The sediment surface (solid line), and thus water depth, is indicated for the mean sea-level curve. A mean subsidence of $3 \mathrm{~m} / 100 \mathrm{ky}$ is inferred in the calculations. A calculation for 40 cycles of the Salève section is presented. For further discussion refer to the text. (B) Fischer plot with cumulative deviation from mean cycle thickness for the same section.

\subsection{Subsidence patterns}

The calculated sea-level curves for all sections display a consistent long-term trend, but in detail they show some variability (Fig. 11A). This may be partly due to different local morphologies and facies distributions on the shallow platform. However, if one assumes that there was at least a regionally homogeneous, eustatic sea-level control, the calculated sea-level curves should be more or less identical. It is therefore suggested that the observed differences in the curves are related to areas of locally enhanced and reduced subsidence on the platform (e.g. Wildi et al., 1989; Pasquier and Strasser, 1997; Hillgärtner, 1999). Consequently, the inferred linear subsidence curves of $3 \mathrm{~m} / 100 \mathrm{ky}$ are modified for each section by hand in such a way that all sea-level curves match as closely as possible the polynomial fit of the calculated sea-level mean (Fig. 11A,B). The resulting subsidence curves clearly display a common pattern with strong differential subsidence of up to $6 \mathrm{~m} / 100$ ky around large-scale sequence-boundary zones Be5 and Be6 (Fig. 11B). Differential subsidence with amplitudes of 3-4 m/100 ky also occurs around sequence-boundary zones $\mathrm{Be} 7, \mathrm{Be} 8$, and Va1.

\subsection{Spectral analysis}

One of the assumptions in this case study is that high-frequency sea-level changes were climatically driven due to insolation changes in the Milankovitch frequency band. If sea-level changes

Fig. 9. Example of the stratigraphic architecture within part of the Chambotte section (for location of the section refer to Fig. 6). Sequence- and cyclostratigraphic interpretation is based on information derived from all correlated sections. Values used to calculate sea-level curves are given in the table. Decompacted sediment thicknesses are indicated in metres, and water-depth is referred to in ranges according to Fig. 2. 


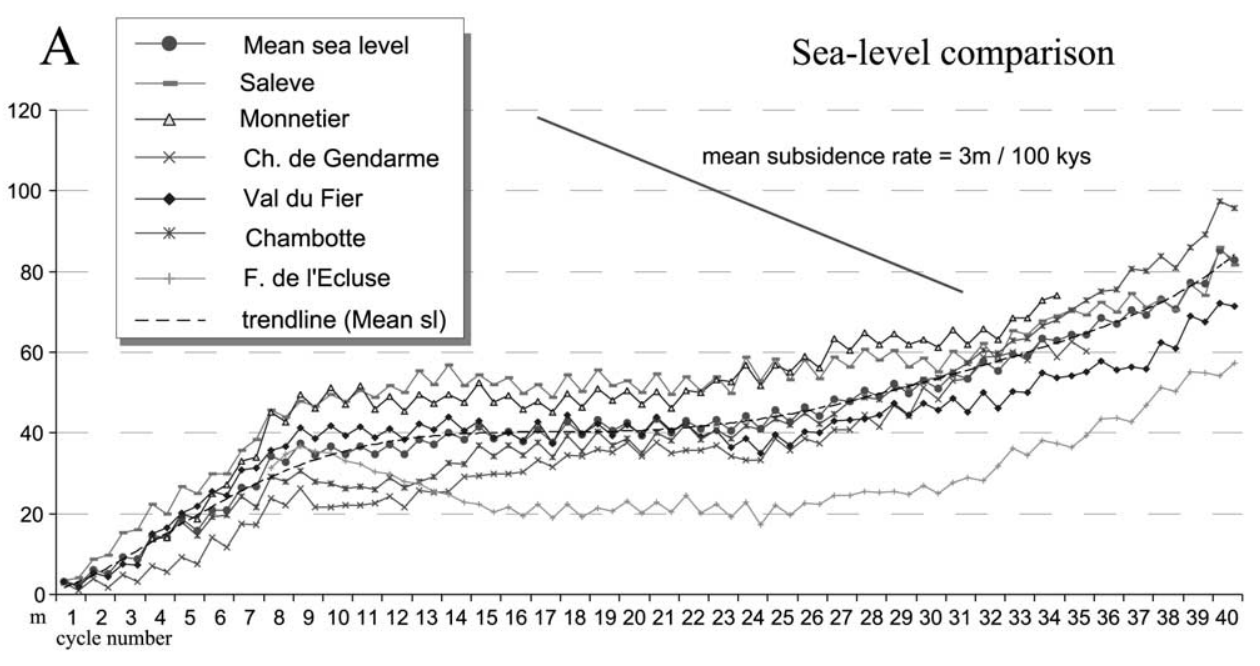

\section{B Mean sea-level curve corrected for differential subsidence}

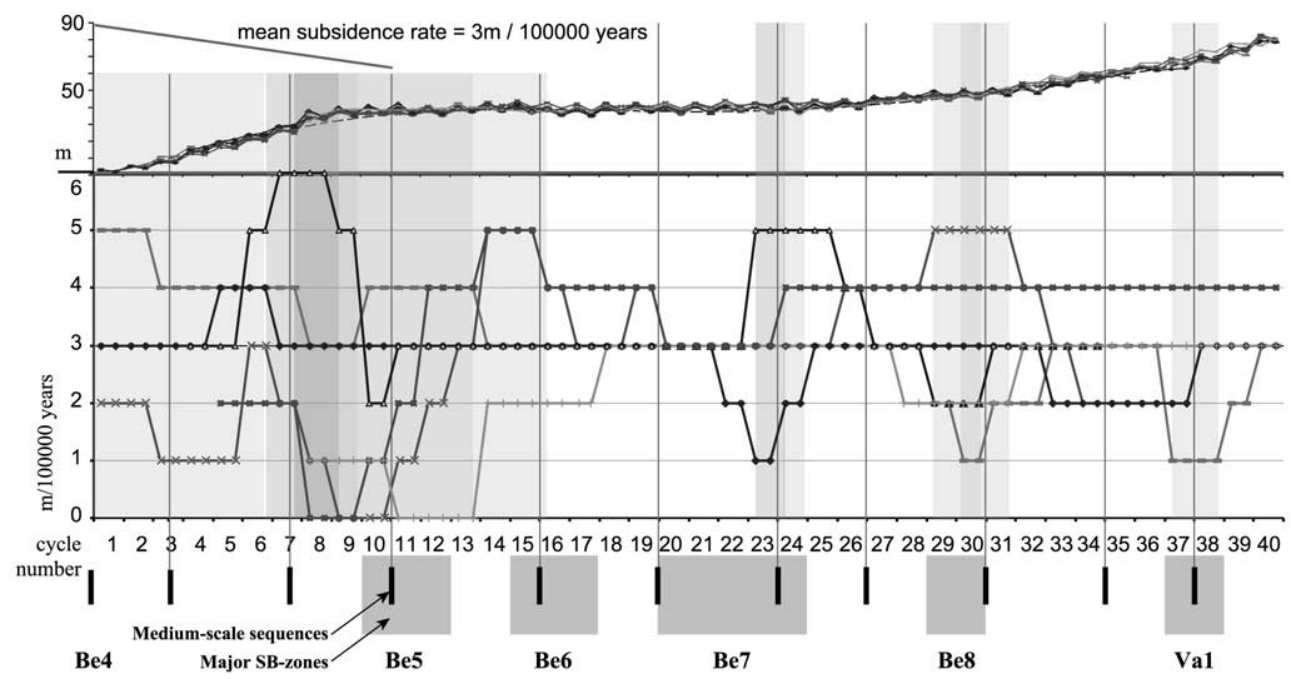

Fig. 11. (A) Comparison of calculated sea-level curves for all sections and the calculated mean sea-level curve. The inferred mean subsidence rate is $3 \mathrm{~m}$ per $100 \mathrm{ky}$. (B) Correction of the individual curves towards an averaged mean sea-level curve (interpreted to reflect the eustatic component of sea-level change) through addition of differential subsidence curves. Times with strong differential subsidence (shaded areas) match some major SB zones. For further discussion refer to text.

were indeed of this origin, then power spectra of the calculated sea-level curves should show the significant periodicities. Spectral analysis of the sea-level curves was carried out with version 2.2 of SPECTRUM, a well-documented programme for the analysis of time series (Schulz and Stattegger, 1997). An additional analysis with a different application built in the LABVIEW environment revealed similar results but is not documented here.

A harmonic analysis of the sea-level data for 40 depositional sequences was carried out for all sections, and for the mean calculated sea-level curve corrected for differential subsidence. For all calculations $\lambda$ was set at 0.4 (Siegel's test factor for 2-3 harmonic components; Schulz and Stattegger, 

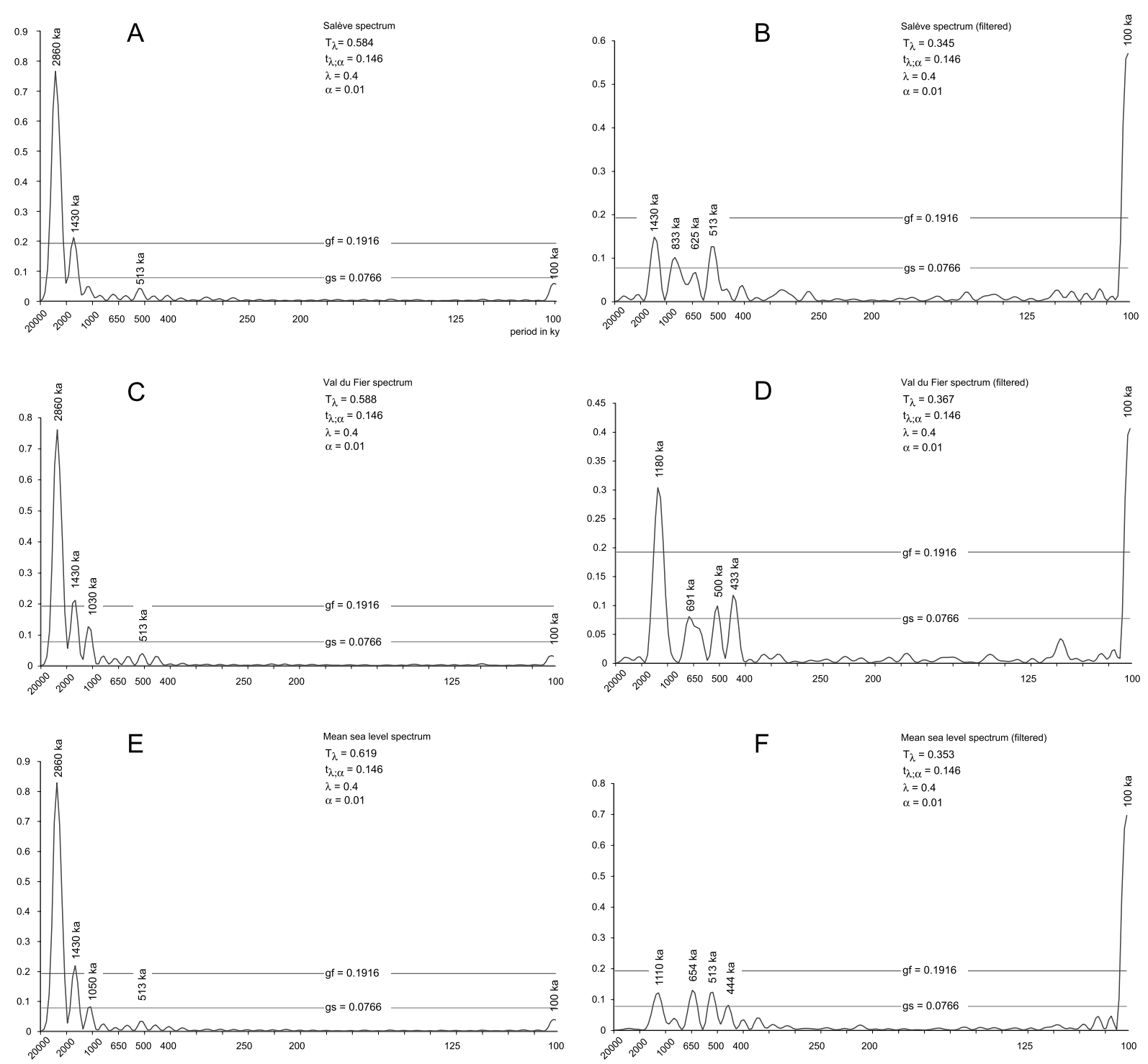

Fig. 12. Spectral analysis of calculated sea-level curves. An example of two sections and the calculated mean sea-level curve are shown. The $x$-axis shows the period in ky, and the $y$-axis the relative power of the spectrum. The periods of selected peaks are labelled separately. The upper and lower horizontal lines show the critical levels for Fisher's (gf) and Siegel's (gs) tests. The nullhypothesis (absence of one or more periodic components) is rejected in all cases since test statistic $\left(T \equiv \mathrm{T}_{\lambda}\right)$ is always greater than the critical value $\left(\mathrm{tc} \equiv \mathrm{t}_{\lambda ; \alpha}\right.$ ) (Schulz and Stattegger, 1997). For discussion of the results refer to the text.

1997), $\alpha$ at 0.01 (factor for statistical tests), and a linear trend was subtracted. Some results of the harmonic analyses are documented in Fig. 12.

The spectra show very dominant peaks at long periods, denoting long-term trends, which, to some extent, mask higher frequencies. Therefore, long-term periods were filtered out to illustrate more clearly significant periods in the higher frequency spectrum (Fig. 12B,D,F). Here, the 100-ky frequency is as prominent as it must be, since it was the initial sampling frequency. Several peaks between 430 and 1430 ky appear consistently in many sections and in the mean sea-level curve (Fig. 12B,D,F). In the unfiltered spectrum, recur- 
rent peaks occur at around $500 \mathrm{ky}$. Although they are within the range of white noise (below the level of significance gs), their consistency in all spectra suggests some importance of this period in the sea-level curves. However, no clear periodicity of the Milankovitch spectrum can be identified, although a few periods occur close to the $400-k y$ frequency band of the second eccentricity cycle (Fig. 12D,F).

\section{Discussion}

\subsection{Potential and shortcomings of the method}

The described method clearly improves presently known approaches to quantifying accommodation changes in cyclic successions. It is the first attempt to reconstruct and quantify high-frequency sea-level changes by taking into account the complexities of natural sedimentary systems. Methods such as that of Goldstein and Franseen (1995) aim for larger-scale variations of sea level and require very specific outcrop conditions. In contrast to traditional accommodation curves, the sea-level curves calculated here acknowledge unfilled accommodation space and decompaction of the sediment. The main advance of the method is the recognition of different cycle types and thus variable patterns of the interaction between accommodation change and accumulation rate. The calculations additionally provide some model-driven feedback, which can reveal inconsistencies in the facies interpretation and the cyclostratigraphic analysis. When applied to numerous sections in one region, patterns of differential subsidence may be recognised and can be integrated in the analysis of platform evolution. In suitable stratigraphic successions, the relation of sea-level changes to changes in the insolation pattern and climate changes may be elucidated.

However, a good part of the method depends on the correct interpretation of facies and waterdepth estimates. This is not an easy task, and errors involved may significantly distort the results. The response of sediment accumulation rates to sea-level changes are also largely interpretative and in future implementations should in- clude several models to constrain error margins. Other possible sources of errors are mistakes in the cyclostratigraphic interpretation and non-recognition of hiatuses and missing sequences (Goldhammer et al., 1993; Strasser et al., 1999). Inaccurate correlations can, of course, significantly alter the results. Despite these shortcomings inherent in every sedimentological and stratigraphical analysis, the high-resolution sea-level curves obtained are more precise than presently available from Fischer plots. Fig. 10 clearly shows that Fischer plots can only provide information about the general trend of accommodation change and should not be confused with sea-level curves (Boss and Rasmussen, 1995).

Additional refinements of the method itself such as an algorithm describing the displacement of the point of maximum accg with rising subsidence rates will be included in the future and will further improve the results.

\subsection{Case study}

The sea-level curves calculated for outcrops on the French Jura platform show a consistent longterm trend for all sections. Through time, accommodation space was created at different rates, but no major sea-level falls are indicated. This result is quite contrary to the first impression obtained by Fischer plots of the same succession (Fig. 10). Local variations in the sea-level curves are interpreted as signatures of differential subsidence, since any high-frequency eustatic sea-level signal should be of regional importance and the same across the whole platform. The differential subsidence curves show an interesting pattern: the highest amplitudes of differential movements cluster around major sequence-boundary zones (Fig. 11). These sequence-boundary zones correspond to the 'third-order' SBs of Hardenbol et al. (1998) that are thought to represent a eustatic sea-level signal (Fig. 6). It is remarkable that presumed regional tectonic activity causing differential subsidence seems to be concentrated at these times. Medium-scale and small-scale SBs can be observed throughout the succession but are best expressed when differential subsidence was significant. Consequently, large-scale, 'third-order' se- 
quences can be interpreted as an effect of the superposition of eustatic high-frequency sea-level variations and regional tectonic activity on the Jura platform, and not as exclusively resulting from eustasy (Hillgärtner, 1999). Nevertheless, it appears that sea-level fluctuations in tune with the 400-ky eccentricity cycle contributed to the formation of the 'third-order' sequences recognised by Hardenbol et al. (1998), since these sequences correspond in many cases to one or several mediumscale sequences (Fig. 11B; Strasser et al., 2001).

Exposure surfaces are generally best expressed in time intervals when the background, long-term relative sea-level rise is slow (between $\mathrm{Be} 5$ and Be8; Fig. 11B). During times of more rapid long-term sea-level rise, discontinuity surfaces are less well marked in the sedimentary record (between $\mathrm{Be} 4$ and $\mathrm{Be} 5$, and between $\mathrm{Be} 8$ and Va1; Fig. 11B). Consequently, the stratigraphic expression of the major differential subsidence occurring before SB Be5 (Fig. 11B) is subdued on the Jura platform.

It is evident that the calculated sea-level signal is only of regional importance and cannot represent a true eustatic signal as long as the analysed sections come from just one platform. However, a high-frequency eustatic component may still be recognisable since regional tectonic patterns commonly are of longer durations (Cloetingh, 1988).

The aim of the spectral analysis of the sea-level curves was to confirm the presence of periodicities in the Milankovitch frequency band, as they are implied from the chronostratigraphy and the analysis of the stacking pattern (see Section 3.3). However, the results do not support such an interpretation. There may be several reasons for this: (1) the length of the time series of only forty sea-level cycles is not enough for a robust harmonic analysis (Schulz and Stattegger, 1997); (2) the errors involved in the sedimentological and stratigraphical interpretation falsify the changes in sea-level amplitudes; (3) the initial sampling frequency of $100 \mathrm{ky}$ is too large to identify other periodicities in the Milankovitch frequency band; (4) the translation of insolation cycles into sealevel fluctuations is such that the original periodicities are distorted and cannot be recognised any more in the sedimentary record; and (5) the fundamental assumption of equal periods for the cycles is false.

\section{Conclusions and outlook}

A method to calculate realistic high-frequency sea-level curves on the basis of detailed facies and cyclostratigraphical analyses is presented. It is suitable for all shallow-marine carbonate successions that show a repetitive ('cyclical') pattern in their stratigraphic architecture. The method includes different types of depositional sequences that represent various combinations of changes in accommodation and sediment accumulation rates, including cases where accommodation space is not entirely filled. Four types of sequences are distinguished: keep-up, catch-up, catch-down, and give-up. The model is based on the assumption that sea-level changes have a nearly sinusoidal pattern, but asymmetry introduced by the superposition of larger-scale trends of sea-level evolution is integrated. Ten different combinations are used to approximate the ranges of variables that are necessary to calculate amplitudes of sea-level variations.

The model is applied to six sections in the Lower Cretaceous of the French Jura platform. Forty small-scale depositional sequences are analysed, each interpreted as representing approximately $100 \mathrm{ky}$. The calculated sea-level curves display a common trend of an initial rise, a long plateau with slow sea-level rise, and a more rapid rise in the Early Valanginian. Amplitudes of differential subsidence are obtained through a correction of local differences in the calculated sea-level curves. Intervals of rapid changes in subsidence cluster around large-scale sequence-boundary zones. It is concluded that these zones, which are correlatable with the 'third-order' SBs of Hardenbol et al. (1998), represent a superposition of high-frequency, probably eustatic sea-level changes and regional tectonic activity. During times of rapid long-term sea-level rise, the expression of discontinuity surfaces created by local differential subsidence is attenuated. Small-scale changes in amplitudes of the sea-level curve do not reveal unequivocal frequencies in the Milankovitch fre- 
quency band, but this may be the result of the unsuitability of the studied succession and a time series too short for robust harmonic analyses.

The aim of this approach is to obtain more precise information on small-scale changes in sea level, and subsidence. These are needed for detailed quantifications of carbonate productivity, sediment accumulation, and sediment flux on ancient platforms, which can then be compared with equivalent processes in recent environments in a more meaningful way. The next step will be to apply this method to a succession where the sedimentary record reflects a more complete spectrum of the Milankovitch frequency band. Ideally, the method will allow comparison of the sea-level record with calculated insolation variations, which may constrain better the interactions between climate change and sea level in greenhouse worlds.

\section{Acknowledgements}

We thank Boris Giacobbo (Giacobbo Microtechnique Engineering) who kindly provided his precious time to help us with the spectral analyses and Adrian Immenhauser for helpful comments. The very constructive and thoughtful reviews of Maurice Tucker and Paul Enos are greatly appreciated and improved the readability of the paper. This study is part of a research project funded by the Swiss National Science Foundation (No. 2056491.99). This financial support is gratefully acknowledged.

\section{References}

Baldwin, B., 1971. Ways of deciphering compacted sediments. J. Sediment. Petrol. 41, 293-301.

Berger, A., Loutre, M.F., Dehant, V., 1989. Astronomical frequencies for pre-Quaternary palaeoclimate studies. Terra Nova 1, 474- 479.

Bond, G.C., Kominz, M.A., 1984. Construction of tectonic subsidence curves for the early Paleozoic miogeocline, southern Canadian Rocky Mountains: Implications for subsidence mechanisms, age of break up, and crustal thinning. Bull. Geol. Soc. Am. 95, 155-173.

Boss, S.K., Rasmussen, K.A., 1995. Misuse of Fischer plots as sea-level curves. Geology 23, 221-224.
Clavel, B., Charollais, J., Busnardo, R., Le Hégarat, G., 1986. Précisions stratigraphiques sur le Crétacé inférieur basal du Jura méridional. Eclogae Geol. Helv. 79, 319-341.

Cloetingh, S., 1988. Intraplate stresses: A tectonic cause for third-order cycles in apparent sea level? In: Wilgus, C.K., Hastings, B.S., Kendall, C.G.St.C., Posamentier, H.W., Ross, C.A., Van Wagoner, J.C. (Eds.), Sea-Level Changes: An Integrated Approach. Soc. Econ. Pal. Min. Spec. Publ. 42, pp. 19-29.

Fischer, A.G., 1964. The Lofer cyclothems of the Alpine Triassic. In: Merriam, D.F. (Ed.), Symposium on Cyclic Sedimentation. Kansas Geol. Surv. Bull. 169, pp. 107149 .

Goldhammer, R.K., 1997. Compaction and decompaction algorithms for sedimentary carbonates. J. Sediment. Res. 67, 26-35.

Goldhammer, R.K., Dunn, P.A., Hardie, L.A., 1990. Depositional cycles, composite sea-level changes, cycle stacking patterns, and the hierarchy of stratigraphic forcing: Examples from Alpine Triassic platform carbonates. Bull. Geol. Soc. Am. 102, 535-562.

Goldhammer, R.K., Lehmann, P.J., Dunn, P.A., 1993. The origin of high-frequency platform carbonate cycles and third-order sequences (Lower Ordovician El Paso Gp, west Texas): Constraints from outcrop data and stratigraphic modeling. J. Sediment. Petrol. 63, 318-359.

Goldstein, R.H., Franseen, E., 1995. Pinning points: A method providing quantitative constraints on relative sea-level history. Sediment. Geol. 95, 1-10.

Gornitz, V., Lebedeff, S., Hansen, J., 1982. Global sea-level trend in the past century. Science 215, 1611-1614.

Gradstein, F.M., Agterberg, F.P, Ogg, J.G., Hardenbol, J., van Veen, P., Thierry, J., Huang, Z., 1995. A Triassic, Jurassic and Cretaceous time scale. In: Berggren, W.A., Kent D.V., Aubry, M.P., Hardenbol, J. (Eds.), Geochronology, Time Scales and Global Stratigraphic Correlation. Spec. Publ. Soc. Econ. Paleontol. Miner. 54, pp. 95-126.

Hardenbol, J., Thierry, J., Farley, M.B., Jacquin, T., De Graciansky, P.-C., Vail, P.R., 1998. Mesozoic and Cenozoic sequence chronostratigraphic framework of European basins. In: De Graciansky, P.-C., Hardenbol, J., Jacquin, T., Vail, P.R., Farley, M.B. (Eds.), Mesozoic and Cenozoic Sequence Stratigraphy of European Basins. Spec. Publ. Soc. Econ. Paleontol. Miner. 60, pp. 3-15.

Hillgärtner, H., 1998. Discontinuity surfaces on a shallow-marine carbonate platform (Berriasian - Valanginian, France and Switzerland). J. Sediment. Res. 68, 1093-1108.

Hillgärtner, H., 1999. The Evolution of the French Jura Platform during the Upper Berriasian to Lower Valanginian: Controlling Factors and Timing. GeoFocus 1, Univ. Fribourg, 203 pp.

Jacobs, D.K., Sahagian, D.L., 1993. Climate-induced fluctuations in sea level during non-glacial times. Nature 361, 710 712 .

Kendall, C.G.St.C., Schlager, W., 1981. Carbonates and relative changes in sea level. Mar. Geol. 44, 181-212.

Le Hégarat, G., 1980. Berriasien. In: Cavelier, J., Roger, J. 
(Eds.), Les étages français et leurs stratotypes Mém. Bur. Rech. géol. min. 109, pp. 96-105.

Le Hégarat, G., 1971. Le Berriasien du Sud-Est de la France. Doc. Lab. Géol. Fac. Sci. Lyon 43, 567 pp.

Martin-Chivelet, J., Osleger, D.A., Montañez, I.P., 2000. Modified Fischer plots as graphical tools for evaluating thickness patterns in stratigraphic successions. J. Geosci. Educ. 48, 179-183.

Moore, C.H., 1989. Carbonate Diagenesis and Porosity. Dev. in Sediment. 46, Elsevier, Amsterdam, 338 pp.

Osleger, D., 1991. Subtidal carbonate cycles: Implications for allocyclic vs. autocyclic controls. Geology 19, 917-920.

Pasquier, J.-B., Strasser, A., 1997. Platform-to-basin correlation by high-resolution sequence stratigraphy and cyclostratigraphy (Berriasian, Switzerland and France). Sedimentology 44, 1071-1092.

Pittet, B., 1994. Modèle d'estimation de la subsidence et des variations du niveau marin: Un exemple de l'Oxfordien du Jura suisse. Eclogae Geol. Helv. 87, 513-543.

Posamentier, H.W., Allen, G.P., James, D.P., 1992. High resolution sequence stratigraphy: The East Coulee Delta, Alberta. J. Sediment. Petrol. 62, 310-317.

Read, J.F., Goldhammer, R.K., 1988. Use of Fischer plots to define third order sea level curves in Ordovician peritidal cyclic carbonates, Appalachians. Geology 16, 895-899.

Read, J.F., Grotzinger, J.P., Bova, J.A., Koerschner, W.F., 1986. Models for the generation of carbonate cycles. Geology $14,107-110$

Remane, J., 1985. Calpionellids. In: Bolli, H.M., Saunders, J.B., Perch-Nielsen, K. (Eds.), Plankton Stratigraphy. Univ. Press, Cambridge, pp. 555-572.

Sadler, P.M, 1994. The expected duration of upward-shallowing peritidal carbonate cycles and their terminal hiatuses. Geol. Soc. Am. Bull. 106, 791-802.

Sadler, P.M., Osleger, D.A., Montañez, I.P., 1993. On the labeling, length, and objective basis of Fischer plots. J. Sediment. Petrol. 63, 360-368.

Schlager, W., 1993. Accommodation and supply - A dual control on stratigraphic sequences. Sediment. Geol. 86, 111136.

Schulz, M., Schäfer-Neth, C., 1998. Translating Milankovitch climate forcing into eustatic fluctuations via thermal deep water expansion: A conceptual link. Terra Nova 9, 228231.
Schulz, M., Stattegger, K., 1997. Spectrum: Spectral analysis of unevenly spaced paleoclimatic time series. Comput. Geosci. 23, 929-945.

Sclater, J.G., Christie, P.A.F., 1980. Continental streching: An explanation of the post-mid-Cretaceous subsidence of the central North Sea Basin. J. Geophys. Res. 85, 3711-3739.

Shackleton, N.J., 1987. Oxygen isotopes, ice volume and sea level. Quat. Sci. Rev. 6, 183-190.

Shinn, E.A., Robbin, D.M., 1983. Mechanical and chemical compaction in fine-grained shallow-water limestones. J. Sediment. Petrol. 53, 595-618.

Soreghan, G.S., Dickinson, W.R., 1994. Generic types of stratigraphic cycles controlled by eustasy. Geology 22, 759-761.

Strasser, A., 1994. Milankovitch cyclicity and high-resolution sequence stratigraphy in lagoonal-peritidal carbonates (Upper Tithonian-Lower Berriasian, French Jura Mountains). Spec. Publ. Int. Assoc. Sedimentol. 19, 285-301.

Strasser, A., Hillgärtner, H., 1998. High-frequency sea-level fluctuations recorded on a shallow carbonate platform (Berriasian and Lower Valanginian of Mount Salève, French Jura). Eclogae Geol. Helv. 91, 375-390.

Strasser, A., Pittet, B., Hillgärtner, H., Pasquier, J.-B., 1999. Depositional sequences in shallow carbonate-dominated sedimentary systems: Concepts and definitions. Sediment. Geol. 128, 201-221.

Strasser, A., Hillgärtner, H., Hug, W., Pittet, B., 2001. Thirdorder depositional sequences reflecting Milankovitch cyclicity. Terra Nova (in press).

Tipper, J.C., 1997. Modeling carbonate platform sedimentation - Lag comes naturally. Geology 25, 495-498.

Tipper, J.C., 2000. Patterns of stratigraphic cyclicity. J. Sediment. Res. 70, 1262-1279.

Trümpy, R., 1980. Geology of Switzerland, Part A. An Outline of the Geology of Switzerland. Wepf, Basel/New York.

Vail, P.R., Audemard, F., Bowman, S.A., Eisner, P.N., PerezCruz, C., 1991. The stratigraphic signatures of tectonics, eustacy, and sedimentology. In: Einsele, G., Ricken, W., Seilacher, A. (Eds.), Cycles and Events in Stratigraphy. Springer, Heidelberg, pp. 617-659.

Wildi, W., Funk, H., Loup, B., Amato, E., Huggenberger, P., 1989. Mesozoic subsidence history of the European marginal shelves of the Alpine Tethys (Helvetic realm, Swiss Plateau and Jura). Eclogae Geol. Helv. 82, 817-840. 